\title{
ISOLASI DAN SELEKSI CENDAWAN ENDOFIT DARI TANAMAN BETADIN (Jatropha multifida L.) DAN POTENSINYA SEBAGAI ANTIMIKROBA
}

\author{
Israwati Harahap, Elsie, Indri Nurjanah
}

Universitas Muhammadiyah Riau

israwatiharahap@umri.ac.id

\begin{abstract}
This research aimed to isolate and select endophytic fungi that potentially as antimicrobial from betadin plants (Jatropha multifida L.). Isolation of endophytic fungi was carried out using surface sterilization and selection of endophytic fungi using well diffusion method. A total of 13 isolates of endophytic fungi were obtained from J. Multifida L. From a total of 13 isolates, 11 isolates were able to inhibit the growth of Candida albicans, 11 isolate was able to inhibit the growth of Staphylococcus aureus and 10 isolates were able to inhibit the growth of Escherichia coli.
\end{abstract}

Keywords: Endophytic fungi, Jatropha multifida L., Antimicrobial

\section{PENDAHULUAN}

Cendawan endofit ialah mikroorganisme yang menghabiskan seluruh atau sebagian siklus hidupnya dengan mengkolonisasi jaringan sehat tumbuhan secara interseluler dan atau intraseluler tanpa membahayakan inangnya. Cendawan endofit mampu menghasilkan senyawa metabolit sekunder yang sama dengan inangnya. Cendawan endofit pada tumbuhan merupakan sumber komponen bioaktif alami yang penting dan baru, salah satunya berupa zat antimikroba. Tumbuhan yang sering dieksplorasi cendawan endofitnya sebagai sumber zat antimikroba tersebut ialah tanaman obat.

Tanaman obat telah diketahui sebagai inang yang baik bagi berbagai cendawan endofit (Hongsheng et al. 2010). Betadin (Jatropha multifida L.) merupakan salah satu tanaman obat yang belum banyak dikenal dan dimanfaatkan secara optimal oleh masyarakat Indonesia. Tanaman betadin diketahui mengandung alkaloid dan flavonoid. Flavonoid merupakan salah satu metabolit sekunder yang terdapat pada tanaman dan merupakan senyawa polar karena mempunyai sejumlah gugus hidroksil, sehingga akan larut dalam pelarut polar seperti etanol dan metanol. Senyawa ini dapat digunakan sebagai antimikroba, obat infeksi pada luka dan antifungi. Selain itu flavonoid juga dapat digunakan sebagai antibakteri, antialergi, sitotoksik, dan anti hipertensi (Rijke, 2005).
Sejauh ini penelusuran dan pemanfaatan senyawa aktif dari tanaman betadin masih terbatas dalam isolasi senyawa yang dihasilkan oleh tanaman betadin tersebut sehingga akan membutuhkan banyak biomassa. Cara yang efisien untuk memperoleh senyawa bioaktif tersebut adalah dengan menggunakan cendawan endofit. Kemampuan mikroorganisme endofit dalam memproduksi senyawa metabolit sekunder sesuai dengan tanaman inangnya merupakan peluang yang sangat baik (Petrini et al., 1992; Ren \& Wen 2001 ).

Manfaat cendawan endofit yang potensial tersebut dapat dimanfaatkan untuk mengobati penyakit infeksi, terutama yang disebabkan oleh bakteri patogen. Sejumlah bakteri patogen telah mengalami resistensi terhadap antibiotik, contohnya adalah resistensi Staphylococcus aureus terhadap oxacillin, tetrasiklin, dan trimetoprim (Shittu et al. 2011). Oleh karena itu, perlu dilakukan isolasi dan seleksi cendawan endofit dari tanaman betadin dan mengetahui potensinya dalam menghasilkan senyawa antimikroba.

\section{METODOLGI PENELITIAN}

\section{Isolasi Cendawan Endofit}

Isolasi cendawan endofit dilakukan dengan mengacu pada Okane et al. (2008). Bagian tanaman betadin yang digunakan adalah batang, daun dan bunga dalam kondisi segar. Sampel 
tanaman dalam keadaan segar dibersihkan dengan air mengalir kemudian dipotong-potong sepanjang 1-3 cm dan dipisahkan menurut bagian tanamannya. Potongan sampel direndam dalam etanol $70 \%$ selama 1 menit, larutan natrium hipoklorit $1 \%$ selama 2 menit, dan dicuci dengan etanol $70 \%$ selama 30 detik. Seluruh sampel direndam kembali dengan aquades steril sebanyak 3 kali pengulangan selama 1 menit. Selanjutnya, bilasan terakhir dari aquades diambil sebanyak $5 \mathrm{ml}$ dan diinokulasi ke cawan Petri yang telah berisi media Malt Extract Agar (MEA) untuk dijadikan blanko. Kemudian sampel batang, daun dan bunga betadin dikeringkan menggunakan tisu steril selama \pm 3 jam. Sampel dipotong-potong dengan ukuran 1-3 $\mathrm{cm}$. Sebanyak 6 potong sampel (6 potong/cawan) dari setiap bagian tanaman diletakkan pada media Malt Extract Agar (MEA) dan diinkubasi pada suhu $25^{\circ} \mathrm{C}$ selama 1 bulan. Ujung hifa dari setiap koloni yang tumbuh diisolasi dan dimurnikan dengan menumbuhkan pada media Potato Dextrose Agar (PDA).

\section{Produksi Senyawa Antimikroba dari Cendawan Endofit}

Setiap isolat cendawan endofit yang tumbuh pada media PDA diambil sebanyak 6 potongan dengan menggunakan sedotan steril dan dimasukkan ke dalam tabung reaksi yang sudah berisi $10 \mathrm{ml}$ media Potato Dextrose Broth (PDB). Kemudian diinkubasi di dalam shaking incubator selama 21-28 hari dengan kecepatan 120 rpm dan suhu $28^{\circ} \mathrm{C}$.

\section{Persiapan Mikroba Uji}

Sebanyak satu ose koloni Candida albicans diinokulasikan ke dalam tabung reaksi yang sudah berisi $10 \mathrm{ml}$ media Potato Dextrose Yeast (PDY) cair, kemudian diinkubasi pada suhu ruang selama 18-24 jam. Sebanyak satu ose koloni Staphylococcus aureus dan Escherichia coli diinokulasikan ke dalam masing-masing tabung reaksi yang sudah berisi $10 \mathrm{ml}$ media Nutrient Broth (NB), kemudian diinkubasi pada suhu $37^{\circ} \mathrm{C}$ selama 24 jam.

\section{Seleksi Untuk Memperoleh Isolat Cendawan Endofit Potensial}

Uji aktivitas antimikroba dari cendawan endofit menggunakan metode sumuran. Candida albicans yang sudah ditumbuhkan pada media PDY cair selama 18-24 jam diambil menggunakan cutton bud. Selanjutnya di swab secara horizontal ke media PDY Agar dan dibiarkan selama 5 menit. Kemudian, media PDY Agar dilubangi dengan menggunakan sedotan steril yang berdiameter $6 \mathrm{~mm}$ sebanyak 3 sumuran percawan. Setiap sumuran diisi dengan $0,1 \mu 1$ dari hasil fermentasi cendawan endofit yang telah ditumbuhkan pada media PDB. Selanjutnya, diinkubasi pada suhu ruang dan diamati zona hambat yang terbentuk selama 2448 jam.

Bakteri uji yang sudah ditumbuhkan pada media NB selama 24 jam diambil dengan menggunakan cutton bud. Selanjutnya di swab secara horizontal ke media NA. Cawan Petri yang sudah berisi media NA dilubangi dengan menggunakan sedotan steril yang berdiameter 6 $\mathrm{mm}$ sebanyak 3 sumuran percawan. Setiap sumuran diisi dengan $0,1 \mu \mathrm{l}$ dari hasil fermentasi isolat cendawan endofit. Kemudian, diinkubasi pada suhu $37^{\circ} \mathrm{C}$ dan diamati zona hambat yang terbentuk selama 24-48 jam.

\section{HASIL DAN PEMBAHASAN}

Isolasi Cendawan Endofit dari Tanaman Betadin (J. multifida L.)

Sebanyak 13 isolat cendawan endofit berhasil diisolasi dari tanaman betadin ( $J$. multifida L.) yaitu 8 isolat diperoleh dari daun, 3 isolat dari bunga dan 2 isolat dari batang (Tabel 3.1).

Tabel 3.1.

Hasil Isolasi Cendawan Endofit dari Tanaman Betadin (J. multifida L.)

\begin{tabular}{|c|c|c|c|}
\hline \multirow{2}{*}{$\begin{array}{l}\text { Kode } \\
\text { isolat }\end{array}$} & \multicolumn{3}{|c|}{$\begin{array}{c}\text { Organ tanaman betadin ( } \mathrm{J} . \\
\text { multifida } \text { L.) }\end{array}$} \\
\hline & Daun & Batang & Bunga \\
\hline IN 001 & - & $\checkmark$ & - \\
\hline IN 002 & - & $\checkmark$ & - \\
\hline IN 003 & - & - & $\checkmark$ \\
\hline IN 004 & - & - & $\checkmark$ \\
\hline
\end{tabular}




\begin{tabular}{|c|c|c|c|}
\hline \multirow{2}{*}{$\begin{array}{l}\text { Kode } \\
\text { isolat }\end{array}$} & \multicolumn{3}{|c|}{$\begin{array}{c}\text { Organ tanaman betadin }(J . \\
\text { multifida } \text { L.) }\end{array}$} \\
\hline & Daun & Batang & Bunga \\
\hline IN 005 & - & - & $\checkmark$ \\
\hline IN 006 & & - & - \\
\hline IN 007 & & - & - \\
\hline IN 008 & & - & - \\
\hline IN 009 & & - & - \\
\hline IN 010 & & - & - \\
\hline IN 011 & & - & - \\
\hline IN 012 & & - & - \\
\hline IN 013 & & - & - \\
\hline $\begin{array}{c}\text { Jumlah } \\
\text { isolat }\end{array}$ & 8 isolat & 2 isolat & 3 isolat \\
\hline
\end{tabular}

Tabel 3.1 menunjukkan bahwa jumlah isolat cendawan endofit yang diperoleh dari bagian daun tanaman betadin lebih banyak dibandingkan dengan batang dan bunga. Hal ini diduga bahwa di daun merupakan tempat utama terjadinya proses fotosintesis pada tumbuhan sehingga pada bagian organ tersebut jumlah nutrisi lebih banyak dibandingkan organ lain dan akan mendukung pertumbuhan cendawan endofit. Noverita et al. (2009), menyatakan bahwa sumber nutrisi yang terdapat di bagian daun lebih banyak atau lebih mendukung untuk pertumbuhan cendawan endofit.

Petrini et al. (1992), menyatakan bahwa kehadiran jenis cendawan endofit dapat dihubungkan dengan kondisi mikrohabitat tanaman inang dan kecocokan genotip antara tanaman inang dan cendawan endofit, sehingga akan berpengaruh terhadap perbedaan dalam kondisi koloni endofit dan tingkat infeksi tanaman inang yang di tempati oleh cendawan endofit pada lokasi yang sama.

Seleksi Isolat Cendawan Endofit dalam Menghasilkan Senyawa Antimikroba

Hasil seleksi dari 13 isolat cendawan endofit yang berhasil diisolasi menunjukkan bahwa 11 isolat mampu menghambat pertumbuhan Candida albicans (Tabel 3.2).
Tabel 3.2.

Uji Aktivitas Antifungi Isolat Cendawan Endofit dari Tanaman Betadin (J. multifida L.) terhadap

C.albicans

\begin{tabular}{ccc}
\hline $\begin{array}{c}\text { Kode } \\
\text { Isolat }\end{array}$ & $\begin{array}{c}\text { Zona Hambat } \\
(\mathbf{m m})\end{array}$ & Kategori \\
\hline IN 001 & - & - \\
\hline IN 002 & $7 \mathrm{~mm}$ & Lemah \\
\hline IN 003 & $9 \mathrm{~mm}$ & Lemah \\
\hline IN 004 & - & - \\
\hline IN 005 & $2 \mathrm{~mm}$ & Lemah \\
\hline IN 006 & $9 \mathrm{~mm}$ & Lemah \\
\hline IN 007 & $11 \mathrm{~mm}$ & Sedang \\
\hline IN 008 & $14 \mathrm{~mm}$ & Sedang \\
\hline IN 009 & $9 \mathrm{~mm}$ & Lemah \\
\hline IN 010 & $8 \mathrm{~mm}$ & Lemah \\
\hline IN 011 & $7 \mathrm{~mm}$ & Lemah \\
\hline IN 012 & $9 \mathrm{~mm}$ & Lemah \\
\hline IN 013 & $19 \mathrm{~mm}$ & Kuat \\
\hline Keteran
\end{tabular}

Keterangan: -: tidak memiliki zona hambat

Tabel 3.2 menunjukkan bahwa isolat IN 013 memperlihatkan aktivitas tertinggi dalam menghambat pertumbuhan C.albicans dengan zona hambat sebesar $19 \mathrm{~mm}$ yang termasuk ke dalam kategori kuat (Gambar 3.1) diikuti oleh isolat IN 008 dan IN 007 dengan zona hambat masing-masing sebesar $14 \mathrm{~mm}$ dan $11 \mathrm{~mm}$. Selanjutnya diikuti oleh isolat IN 002, IN 003, IN 005, IN 006, IN 009, IN 010, IN 011 dan IN 012 yang termasuk ke dalam kategori lemah dan 2 isolat yaitu IN 001 dan IN 004 tidak mampu menghambat pertumbuhan C.albicans. Alfiah et al. (2015), menyatakan bahwa daerah hambat yang terbentuk $<10 \mathrm{~mm}$ termasuk ke dalam kategori lemah, 10-15 mm termasuk ke dalam kategori sedang, 16-20 mm masuk dalam kategori kuat, dan >20 mm termasuk ke dalam kategori sangat kuat. 


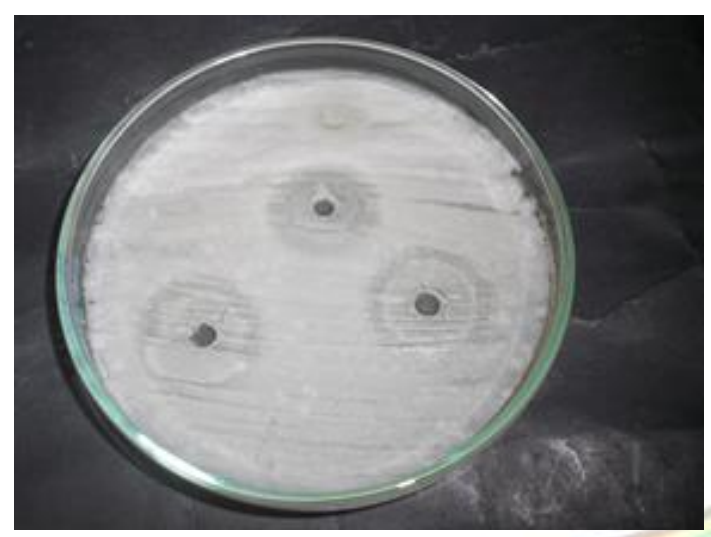

Gambar 3.1. Uji aktivitas antifungi isolat IN 013 terhadap pertumbuhan C.albicans

Zona hambat yang terbentuk dari senyawa antifungi yang dihasilkan oleh masing-masing isolat memiliki diameter yang berbeda-beda. Terbentuknya diameter yang berbeda-beda pada hasil pengamatan uji aktivitas antifungi dikarenakan kemampuan isolat dalam menghambat pertumbuhan C.albicans juga berbeda-beda. Menurut Sugiyanto (2007), cendawan endofit mampu menghasilkan aktivitas antifungi, antibakteri, hormon pertumbuhan tanaman dan insektisida

Uji aktivitas antibakteri dari 13 isolat yang berhasil diisolasi menunjukkan bahwa 10 isolat mampu menghambat pertumbuhan Escherichia coli dan 11 isolat mampu menghambat pertumbuhan Staphylococcus aureus (Tabel 3.3).

Tabel 3.3. Uji Aktivitas Antibakteri Isolat Cendawan Endofit dari Tanaman Betadin $(J$. multifida L.)

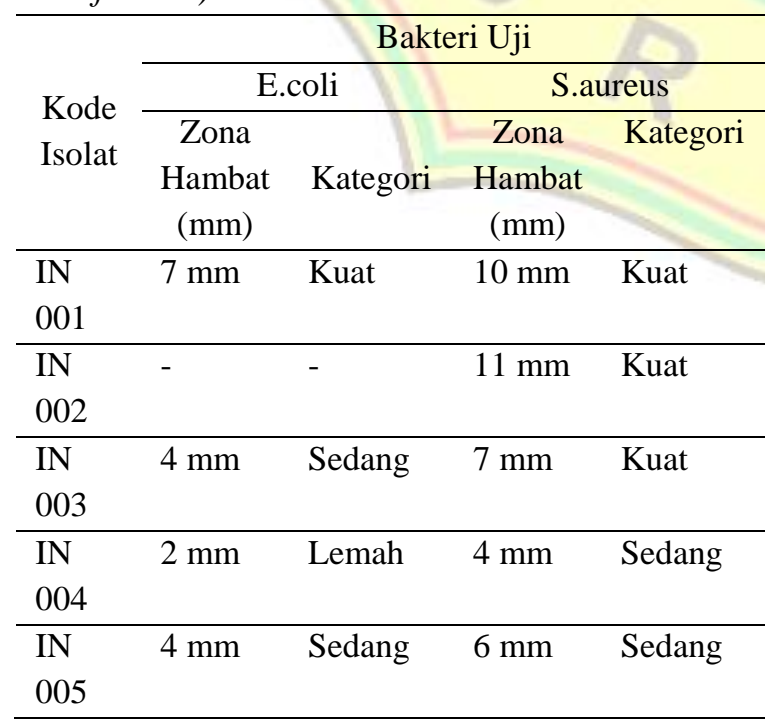

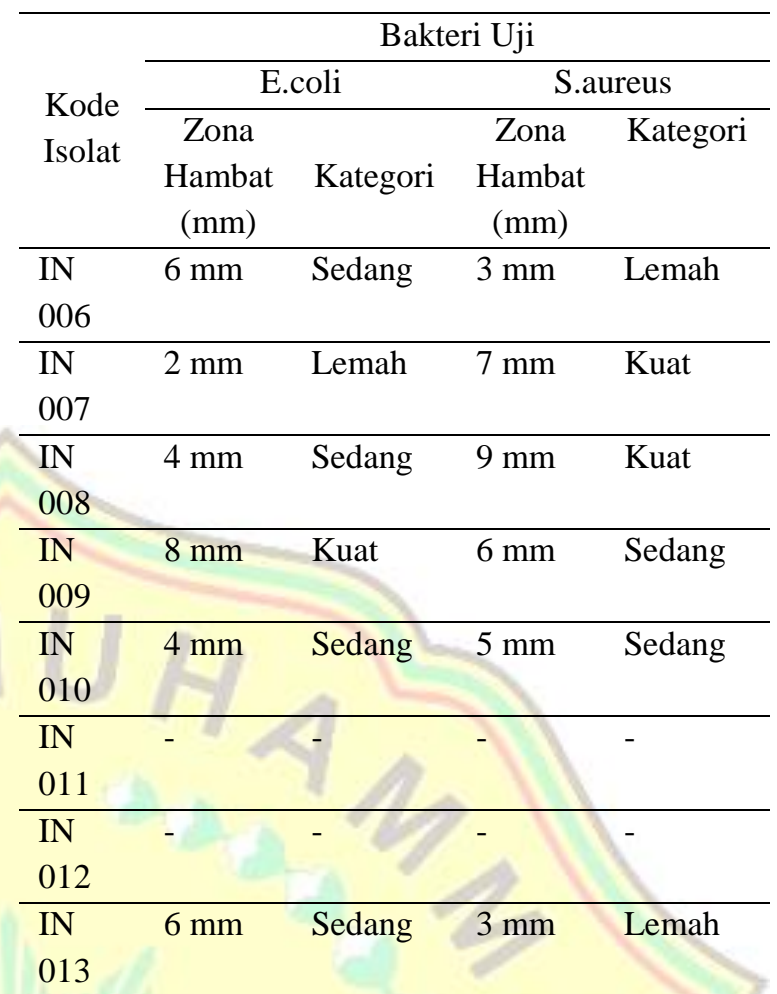

Keterangan: -: tidak memiliki zona hambat

Tabel 3.3. menunjukkan hasil uji aktivitas antibakteri dari cendawan endofit yang mampu menghambat pertumbuhan E.coli, diperoleh 2 isolat yang termasuk ke dalam kategori kuat yaitu IN 001 dan IN 009 dengan diameter masingmasing sebesar $7 \mathrm{~mm}$ dan $8 \mathrm{~mm}, 6$ isolat termasuk ke dalam kategori sedang (IN 003, IN 005, IN 006, IN 008, IN 010, IN 013), 2 isolat dikategorikan lemah (IN 004, IN 007), dan 3 isolat (IN 002, IN 011, IN 012) tidak menunjukkan adanya zona hambat. Isolat yang mampu menghambat pertumbuhan S.aureus yang masuk ke dalam kategori kuat yaitu 5 isolat (IN 001, IN 002, IN 003, IN 007, IN 008) dengan diameter masing-masing $10 \mathrm{~mm}, 11 \mathrm{~mm}, 7 \mathrm{~mm}$ dan 9. Empat isolat masuk ke dalam kategori sedang (IN 004, IN 005, IN 009, IN 010), 2 isolat dikategorikan lemah (IN 006, IN 013) dan 2 isolat (IN 011, IN 012) tidak memperlihatkan zona hambat. Pan et al. (2009) menyatakan bahwa diameter zona hambat 0-3 mm masuk ke dalam kategori lemah, 3-6 mm dikategorikan sedang dan > $6 \mathrm{~mm}$ masuk ke dalam kategori kuat. Kisaran zona hambat yang dihasilkan oleh 13 isolat cendawan endofit tersebut adalah $3 \mathrm{~mm}-11$ $\mathrm{mm}$. 

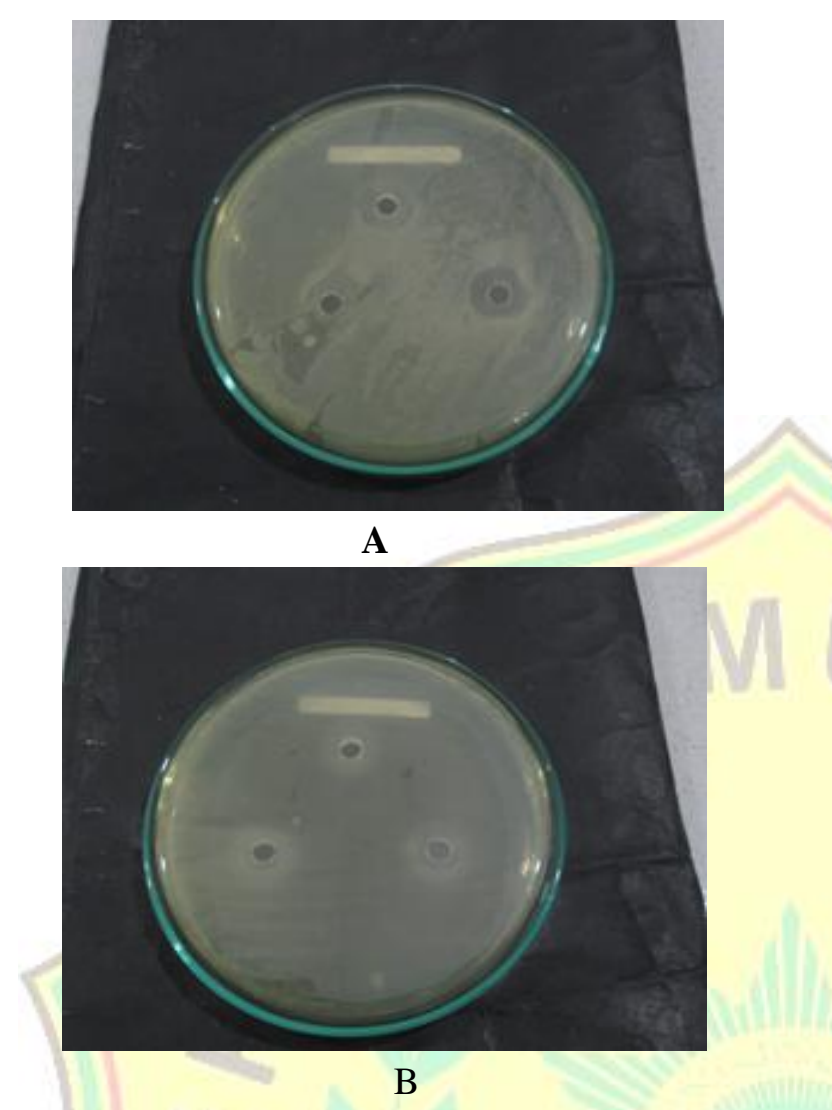

Gambar 3.2. Uji aktivitas antibakteri terhadap E.coli dari isolat IN 9 (A) dan Uji aktivitas antibakteri terhadap S.aureus dari isolat IN 2 (B)

Zona hambat yang terbentuk menunjukkan aktivitas suatu senyawa antibakteri dalam menghambat pertumbuhan atau membunuh bakteri patogen. Menurut (Prihatiningtias \& Wahyuningsih, 2006), metabolit sekunder yang dihasilkan cendawan bersifat bioaktif, salah satunya dapat berupa senyawa antimikroba yang mampu menghambat atau membunuh mikroorganisme patogen.

Hasil pengamatan diameter zona hambat yang dihasilkan oleh cendawan endofit terhadap bakteri gram positif secara umum lebih besar dari pada bakteri gram negatif. hal ini diduga dikarenakan oleh komponen penyusun dinding sel dari masing-masing bakteri tersebut berbeda. menurut (Jawetz et al., 2004) bahwa bakteri gram positif memiliki struktur dinding sel berlapis tunggal dan mengandung lipid yang rendah yaitu $1-4 \%$, sedangkan pada bakteri gram negatif mempunyai dinding sel yang berlapis tiga yaitu lipoprotein, membran luar fosfolipid dan lipopolisakarida serta kandungan lipid yang tinggi yaitu $11-22 \%$ sehingga memudahkan senyawa antibakteri untuk masuk ke dalam sel bakteri gram positif.

Isolat yang tidak menunjukkan adanya zona hambat di sekitar sumuran pada uji aktivitas antibakteri yang telah dilakukan, diduga isolat cendawan endofit tersebut memiliki kandungan senyawa bioaktif yang berbeda-beda kemampuannya dalam menghambat pertumbuhan E.coli dan S.aureus. Menurut Son \& Cheah (2002), bahwa tidak terbentuknya zona hambat ketika uji aktivitas antimikroba yang telah dilakukan bukan karena cendawan tersebut tidak memiliki kandungan senyawa aktif, namun jumlahnya lebih kecil atau mengandung senyawa aktif potensial yang lain. Kemampuan dalam menghambat pertumbuhan mikroba dapat dipengaruhi oleh berbagai faktor diantaranya konsentrasi zat antimikroba, aktifitas metabolit bakteri, serta fisik dan kimia makanan termasuk pH, suhu, kadar air, jenis dan jumlah senyawa di dalamnya (Frazier \& Westhoff, 1988).

\section{SIMPULAN DAN SARAN}

Berdasarkan hasil penelitian yang telah dilakukan dapat diambil kesimpulan yaitu 13 isolat cendawan endofit berhasil diperoleh dari tanaman betadin (Jatropha multifida L.) yang terdiri dari 8 isolat ditemukan pada daun 3 isolat dari bunga dan 2 isolat ditemukan pada batang. Seleksi dari 13 isolat cendawan endofit yang berpotensi penghasil senyawa antimikroba menunjukkan bahwa 11 isolat mampu menghambat pertumbuhan Candida albicans, 11 isolat mampu menghambat pertumbuhan Escherichia coli dan 10 isolat mampu menghambat pertumbuhan Staphylococcus aureus.

Sepuluh isolat yang berhasil diisolasi dari tanaman betadin memiliki potensi yang berbeda dalam menghasilkan senyawa antimikroba. Oleh karena itu, perlu dilakukan penelitian lanjutan untuk mengidentifikasi semua isolat yang telah berhasil diisolasi. 


\section{UCAPAN TERIMA KASIH}

Penulis mengucapkan terima kasih kepada Universitas atas bantuan dana penelitian Internal yang diberikan sehingga penelitian ini dapat diselesaikan.

\section{DAFTAR PUSTAKA}

Alfiah, R. R., Khotimah, S. dan Turnip, M. 2015. Efektivitas Ekstrak Metanol Daun Sembung Rambat (Mikania micrantha Kunth) Terhadap Pertumbuhan Jamur Candida albicans. Jurnal Protobiont. Vol. 4. No. 1. Hal 53.

Hongsheng Y, Lei Z, Lin L, Chengjian Z, Lei G, Wenchao L, Peixin S, Luping Q. 2010. Recent developments and future prospects of antimicrobial metabolites produced by endophytes. Microbiol Res 165:437 449.doi:10.1016/j.micres. 2009.11.009

Jawetz, E., J.L. Melnick., E.A. Adelberg.,G.F. Brooks., J.S . Butel., dan L.N. Ornston. 2004. Mikrobiologi Kedokteran. Edisi ed. 20 (Alih bahasa: Nugroho \& R.F.Maulany). Jakarta: Penerbit Buku Kedokteran EGC.

Noverita, D. Fitria, dan E. Sinaga. 2009. Isolasi dan Uji Aktivitas Antibakteri Jamur Endofit Dari Daun dan Rimpang Zingiber ottensii Val. Jurnal Farmasi Indonesia Vol. 4 No. 4: 171-176.

Okane, I., Srikitikulchai, P., Toyama, K., Læssøe, T., Sivichai, S., Jones, H.H., Nakagiri, A., Potacharoen, W., Suzuki, K. 2008. Study of endophytic Xylariaceae in Thailand: diversity and taxonomy inferred from rDNA sequence analyses with saprobes forming fruit bodies in the field. The Mycological Society of Japan and Springer 49:359-372.

Pan, X., Chen, F., Wu, T., Tang, H., and Zhao, Z.
2009. The acid, Bile Tolerance and Antimicrobial property of Lactobacillus acidophilus NIT. J. Food Control 20: 598-602.

Petrini O, Thomas NS, Toti L, Viret O. 1992. Ecology, metabolite production and substrat utilization in endophytic fungi. Nat toxin. 1:185-196.

Prihatiningtias, W dan M. S. H. Wahyuningsih. 2006. Prospek Mikroba Endofit Sebagai Sumber Senyawa Bioaktif. Artikel Kesehatan. Universitas Gadja Mada. Yogyakarta

Rijke E. 2005. Trace-level Determination of Flavonoids and Their Conjugates Application ti Plants of The Leguminosae Family. Amst erdam: Universitas Amst erdam.

Shittu AO, Okon K, Adesida S, Oyedara O, Witte W, Strommenger B, Layer F, Nubel U. 2011. Antibiotic resistence and molecular epidemiology of Staphylococcus aureus in Nigeria. BMC Microbiol 11(92):1-8.doi:10.1186/14712180-11-92

Son R. dan Cheah YK. 2002. Preliminary Screening of Endophytic Fungi from Medical Plants in Malaysia for Antimicrobial and Antitumor Activity. Malaysian Journal of Medical Sciences, 9(2): 23-33.

Sugiyanto, N.E. 2007. Isolasi dan Determinasi Berbagai Jamur Endofit Dari Tanaman Aglaia Elliptica, Aglaia Eusideroxylon, Aglaia Odorata dan Aglaia Odoratissima. Faculty of Pharmacy Airlangga University. http://www.library.unair.ac.id. Akses tanggal 10 Juli 2016 